Research Article

\title{
Assessment of adolescent problems in tribal adolescent girls: a cross sectional study
}

\author{
Swarnalata Das ${ }^{1}$, Sanjukta Mishra ${ }^{2}$, Aswini Kumar Mohanty ${ }^{1}$, Soumya Sibani Sahoo $^{3}$
}

${ }^{1}$ Department of Paediatrics, Kalinga Institute of Medical Science, Bhubaneswar, Odisha, India
${ }^{2}$ Department of Biochemistry, Kalinga Institute of Medical Science, Bhubaneswar, Odisha, India
${ }^{3}$ Department of Microbiology, S.C.B. Medical College, Cuttack, India

Received: 01 April 2016

Accepted: 11 April 2016

*Correspondence:

Dr. Sanjukta Mishra,

E-mail: sanjuktamisra@gmail.com

Copyright: (C) the author(s), publisher and licensee Medip Academy. This is an open-access article distributed under the terms of the Creative Commons Attribution Non-Commercial License, which permits unrestricted non-commercial use, distribution, and reproduction in any medium, provided the original work is properly cited.

\section{ABSTRACT}

Background: Adolescence is a period of physical, psychological development from puberty to adulthood. There is paucity of information regarding the prevalence of behavioral, physical problems in tribal adolescents, more specifically in tribal adolescent girls, who form a different set from the mainstream section. Aim of the present study was to assess psychosocial, emotional and family life knowledge about adolescent tribal girls. Moreover it also investigated the health status and spectrum of various other problems faced by them.

Methods: Sample for the study comprised of 170 tribal adolescent girls. They were selected randomly from the age group 10-19 years according to their accommodation in girl's hostel. They were further divided into early (10-14 years) and elder (15-19 years) adolescents. Data were collected on predesigned, semi-structured questionnaire method. Study was undertaken by conducting face-to face in depth interviews of selected study population by the investigator. Data were analyzed statistically by using percentage, proportions and chi-square test. Present crosssectional study was conducted in a tribal residential school at Bhubaneswar, Odisha.

Results: Data revealed that most of tribal girls belong to low socio-economic status. Various physical problems and psychosocial problems were found to be significantly higher. Elder adolescents greatly lack information related to proper age of marriage and childbirth. Menstruation related problems and respiratory problems were found to be most prevalent in older and young group respectively.

Conclusions: This gives an insight to implement adolescent friendly effective awareness programme to screen routine adolescent health problems.

Keywords: Adolescence, Prevalence, Respiratory problem

\section{INTRODUCTION}

Adolescence, a period between 10-19 years of age, signifies physical growth, biological growth, sexual maturation and social transition (WHO, 1989). ${ }^{1}$ It accounts for one fifth of the world's population and around $21 \%$ of population in India (243 millions). ${ }^{2}$ Adolescence is the most vulnerable stage from the point of view of health, as physical problems like delayed growth, acne and sexual maturity related problems occur. Moreover behavioral and emotional problems like drug abuse, criminal activity, suicidal tendency, teenager pregnancy, violence and other risk taking behaviors are also quiet common at this stage. ${ }^{3}$ Being shy and being confused about their physical and psychosocial changes, they do not find a congenial atmosphere for consulting and sharing their problems. This might be accentuated by illiteracy, ignorance, lack of awareness and unfavorable attitude. Such kind of problems should be recognized and addressed adequately though medical and social support, to ensure them to build a safe, happy, healthy life. Thus, 
preparing them for undertaking bigger challenges in forthcoming adulthood.

As stated previously, India has a larger population of adolescents in world. Of all the states of India, Odisha has the largest number of tribes (as many as 62), which constitute $22.3 \%$ of the total population in the state. ${ }^{4}$ More so tribal women constitute about half of the total tribal population. Many research activities have been conducted so far to examine the prevalence of emotional and behavioral problems on mainstream adolescent section, focusing the influence of different demographic variables with different cast and religion. ${ }^{5,6,7}$ It has therefore been realized to assess various physical as well as non-physical problems of adolescent tribal population (more specifically girls), who form a different set from the mainstream section. Keeping in view the findings of the above studies, we felt the need to explore more into tribal population of Odisha. Since more of such data were not available for this region, the present research study was planned for adolescent tribal girls specifically in the age group 10-19 years. This research study definitely gives an insight to problems faced by tribal adolescent girls, which might help to manage the situation.

\section{Aim of study}

1. To assess psychosocial, emotional and family life knowledge about adolescent tribal girls.

2. To know about the spectrum of problems faced by them.

3. To find out determinants and several risk factors associated with the problem.

4. To plan for an effective intervention, prevention and management of their problems.

\section{METHODS}

It was a cross sectional study and was carried out in Kalinga Institute of Social Science, a tribal residential school at Bhubaneswar, Odisha. Principal of the school was explained about purpose and nature of the study. A valid consent was taken to conduct the study. Study population comprised of 170 tribal adolescent girls from the aforementioned school. Girls were randomly selected from the age 10-19 years, according to their accommodation arrangement in girl's hostel. They were further divided into two groups (10-14 years and 15-19 years) as their ages were not very accurate to classify them into early, middle and late adolescents. If a designated subject was not cooperative or not willing to give consent during the visit, she was considered as nonrespondent and was excluded from the study. Predesigned, pre-tested and semi structured questionnaire method was used to collect the data. Two sets of questionnaire were given to girls suitable for their age group. A lady teacher (who usually stays with the girls) was assigned for the smooth conduction of the study. Before distribution of questions, girls were explained thoroughly. The study was undertaken in the classroom in presence of the teacher by conducting face-to-face indepth interviews of selected study population, after obtaining informed consent from the concerned adolescent girls. Interviews were scheduled with prior coordination with principal and the assigned lady teacher of the school. Moreover, their confidentiality was taken care of by hiding their names on the response sheet. They were asked to drop their response sheet in a drop box before they were taken for analysis. All the data were recorded in MS excel and was later converted into statistical software for ease of analysis. Keeping in view of aims and objectives, blinded data were analyzed and then interpreted. Calculation of percentage, proportion, Chi-square test with Yate's correction was used for statistical analysis. Ethical approval and prior permission to carry out the study was sought from Institutional research committee.

\section{RESULTS}

All the study adolescent population was interviewed and the response rate was $100 \%$. The results of the present research have been presented under various sections. Out of 170 study participants, a total of 80 girls (47\%) belong to young adolescent (10-14yrs) group and 90 girls $(52.9 \%)$ belong to older group (15-19years) age group. Observations regarding early adolescents (10-14 years) were as follows:

Table 1: Physical problems vs socio economic background (10-14 years).

\begin{tabular}{|c|c|c|c|c|c|c|c|c|}
\hline \multirow{3}{*}{ Physical Problems } & \multirow{3}{*}{ No } & \multirow{3}{*}{$\%$} & \multicolumn{6}{|c|}{ Socio-economic background } \\
\hline & & & \multicolumn{2}{|c|}{ Low } & \multicolumn{2}{|c|}{ Middle } & \multicolumn{2}{|c|}{ High } \\
\hline & & & No & $\%$ & No & $\%$ & No & $\%$ \\
\hline $\begin{array}{l}\text { Physical problems associated } \\
\text { during menstruation }\end{array}$ & 5 & $6.25 \%$ & 3 & $60 \%$ & 2 & $40 \%$ & - & - \\
\hline Respiratory problems & 50 & $62.50 \%$ & 41 & $82 \%$ & 9 & $18 \%$ & - & - \\
\hline Chest diseases & 2 & $2.50 \%$ & 2 & $100 \%$ & - & - & - & - \\
\hline Acne & 10 & $12.50 \%$ & 8 & $80 \%$ & 2 & $20 \%$ & - & - \\
\hline Ophthalmic problems & 15 & $18.75 \%$ & 11 & $73.34 \%$ & 4 & $26.67 \%$ & - & - \\
\hline Dental problems & 18 & $22.50 \%$ & 13 & $72.23 \%$ & 5 & $27.78 \%$ & - & - \\
\hline
\end{tabular}


Table 2: Non-physical problems vs socio economic background (10-14 years).

\begin{tabular}{|c|c|c|c|c|c|c|c|c|c|}
\hline \multirow{3}{*}{\multicolumn{2}{|c|}{ Non-physical problems }} & \multirow{3}{*}{ No. } & \multirow{3}{*}{$\%$ age } & \multicolumn{6}{|c|}{ Socio-economic background } \\
\hline & & & & \multicolumn{2}{|c|}{ Low } & \multicolumn{2}{|c|}{ Middle } & \multicolumn{2}{|c|}{ High } \\
\hline & & & & No. & $\%$ age & No. & $\%$ age & No. & $\%$ age \\
\hline $\mathrm{a}$ & $\begin{array}{l}\text { Frequent feeling of } \\
\text { loneliness }\end{array}$ & 9 & $11.25 \%$ & 5 & $55.56 \%$ & 4 & $44.45 \%$ & - & - \\
\hline $\mathrm{b}$ & Depression & 15 & $18 \%$ & 13 & $92.86 \%$ & 2 & $7.15 \%$ & - & - \\
\hline $\mathrm{c}$ & Suicidal tendency & 2 & $2.5 \%$ & 2 & $100 \%$ & - & - & - & - \\
\hline $\mathrm{d}$ & Insomnia & 3 & $3.75 \%$ & 1 & $33.34 \%$ & 2 & $66.67 \%$ & - & - \\
\hline e & Fight with friends & 27 & $33.75 \%$ & 24 & $88.89 \%$ & 3 & $11.12 \%$ & - & - \\
\hline \multirow[t]{4}{*}{$\mathrm{f}$} & Desire for change & & & & & & & - & - \\
\hline & Personality & 13 & $16.25 \%$ & 12 & $92.31 \%$ & 1 & $7.70 \%$ & - & - \\
\hline & Life style & 37 & $46.25 \%$ & 27 & $72.98 \%$ & 10 & $27.03 \%$ & - & - \\
\hline & Face and figure & 6 & $7.50 \%$ & 6 & $100 \%$ & - & - & - & - \\
\hline $\mathrm{g}$ & $\begin{array}{l}\text { Absence of } \\
\text { knowledge about } \\
\text { menstruation }\end{array}$ & 34 & $42.50 \%$ & 29 & $85.30 \%$ & 5 & $14.71 \%$ & - & - \\
\hline $\mathrm{h}$ & $\begin{array}{l}\text { Change of gender } \\
\text { in next life }\end{array}$ & 31 & $38.75 \%$ & 27 & $87.10 \%$ & 4 & $12.91 \%$ & - & - \\
\hline
\end{tabular}

Socioeconomic status: Majority $(81.25 \%)$ belong to low economic status, $18.75 \%$ belong to middle economic status and none from higher status.

Literacy status: Fathers of 24/80 (30\%) and mothers of $12 / 80(15 \%)$ were found to complete high school. That apart, fathers of $22 / 80(27.5 \%)$ and mothers of $41 / 80$ $(51.2 \%)$ of them were illiterate. One more significant finding was that fathers, mothers of only $1 / 80(1.25 \%)$ and $1 / 80(1.25 \%)$ respectively had attained literacy up to graduation level or above.

Occupation: Occupation of fathers of $37 / 80$ and 40/80 adolescents was agriculture and labor respectively while majority mothers were housewives in 68/80 (85\%) cases.

Table-3: Physical problems vs socio economic background (15-19 years).

\begin{tabular}{|c|c|c|c|c|c|c|c|c|}
\hline \multirow{3}{*}{ Physical problems } & \multirow{3}{*}{ No. } & \multirow{3}{*}{$\%$ age } & \multicolumn{6}{|c|}{ Socio-economic background } \\
\hline & & & \multicolumn{2}{|l|}{ Low } & \multicolumn{2}{|c|}{ Middle } & \multicolumn{2}{|c|}{ High } \\
\hline & & & No. & $\%$ age & No. & $\%$ age & No. & $\%$ age \\
\hline $\begin{array}{l}\text { Physical problems } \\
\text { associated during } \\
\text { menstruation }\end{array}$ & 70 & $77.78 \%$ & 58 & $82.86 \%$ & 12 & $17.15 \%$ & - & - \\
\hline Respiratory problems & 3 & $3.34 \%$ & 2 & $66.67 \%$ & 1 & $33.33 \%$ & - & - \\
\hline Chest diseases & 6 & $6.67 \%$ & 4 & $66.67 \%$ & 2 & $33.33 \%$ & - & - \\
\hline Acne & 29 & $32.23 \%$ & 26 & $89.66 \%$ & 3 & $1034 \%$ & - & - \\
\hline Ophthalmic problems & 19 & $21.12 \%$ & 15 & $78.95 \%$ & 4 & $21.06 \%$ & - & - \\
\hline Dental problems & 25 & $27.78 \%$ & 18 & $72 \%$ & 7 & $28 \%$ & - & - \\
\hline
\end{tabular}

Family types: As evident from the study, 45/80(56.2\%) adolescent girls belong to nuclear family whereas $23 / 80$ $(28.7 \%)$ and $12 / 80(15 \%)$ were from extended family and joint family respectively. According to the distribution of tribal girls as per their tribes, majority of them 24/80 (30\%) were from Santhal community followed by $15 / 80$ (18.7\%) from Kandha community. Very few numbers from other tribes like Munda, Kolha, Desia, bhuyan, saora, jatapi, matia etc.

Physical problems: Table 1 elaborates several physics problems faced by tribal adolescent girls. Majority of adolescent tribal girls 50/80 $(62.5 \%)$ had respiratory problems, $18 / 80(22.5 \%)$ had dental problems, 15/80 
(18.7\%) had ophthalmic problems and 10/80 (12.5\%) girls had minor problems like acne. It was also noted that few of them 5/80 (6.25\%) had problems like dysmenorrhea, breast tenderness, which is associated with menstruation. Many of them had more than one physical problem.

Non-physical problems: The study population from the residential boarding school was homogeneous having almost similar living condition. Observation regarding several non-physical problems was that, 34/80 (38.75\%) study adolescents were not aware about menstruation as most of the girls belong to early adolescents (10-14 years). When enquired about their future desire, it was noted that a larger number of adolescents 56/80 were interested for a change in personality and life style. Moreover $31(38.7 \%)$ girls wanted to have a change of gender (male gender) in next life. Upon questioning, we noted 15/80 (18\%), 27/80 (33.7\%), 9/80 (11.2\%) cases of depression, fight with friends and frequent feeling of loneliness respectively amongst them.

Observations regarding older adolescents (15-19 years) were as follows:

Socioeconomic status: Majority 72/90 (80\%) girls were from low economic status, 18/90 (20\%) study participants were from middle economic status and none from higher economic status.

Literacy status: Fathers of 23/90 (25.5\%) and mothers of $17 / 90(18.8 \%)$ were found to complete high school. Fathers of $14 / 90(15.5 \%)$ and mothers of $41 / 90(45.5 \%)$ of them were illiterate. Fathers of only $3 / 80$ (1.25\%) had attained literacy up to graduation level or above. No mother of this category had gone to this education level.
Family types: As noted during questioning the elder tribal adolescent girls, 59/90 (63.3\%) belong to nuclear family whereas $19 / 90(28.7 \%)$ and $12 / 90(13.3 \%)$ were from joint family and extended family respectively. According to the distribution of tribal girls as per their tribes, majority of them $34 / 90(37.7 \%)$ were from Santhal community followed by $9 / 90(10 \%)$ from Ganda and 8 $(8.8 \%)$ of them from Kolha community. Very few numbers from other tribes like Munda, Kolha, Desia, bhuyan, saora, jatapi, matia etc.

Knowledge of hygiene: Assessment regarding use of sanitary napkins during menstruation, it was observed that 48/90 (53\%) elder girls used sanitary pad/napkin, 20 $(22.2 \%)$ girls used both pad and cloth, 12 (13.3\%) on clean cloth and only $10(11 \%)$ on any ordinary cloth. Majority of them $39 / 90(43.3 \%)$ change the napkin minimum thrice.

Reproductive knowledge: When questioned, most of the elder girls $54(60 \%)$ were found to be unaware about the proper age to become a mother. Surprisingly few of them $19(21 \%)$ did not know minimum age for marriage and quiet a good number of elder girls $29(32 \%)$ lack the knowledge about contraception.

Physical problems: Table 3 explains the common physical problems encountered by older adolescent girls aged 15-19 years. In this study population, 70/90 $(77.78 \%)$ had menstruation related problems of which dysmenorrhea was a major common complaint. Apart from that, other de3observations noted were acne in 29 $(32.3 \%)$ cases, dental problems in $25(27.78 \%)$ cases and ophthalmic problems in $21.2 \%$ girls. Unlike young adolescents, respiratory problems were negligible in older group.

Occupation: Significantly majority mothers $87 / 90$ $(96.6 \%)$ were house wives

Table 4: Non-physical problems vs socio economic background (15-19 years).

\begin{tabular}{|c|c|c|c|c|c|c|c|c|c|}
\hline \multirow{3}{*}{\multicolumn{2}{|c|}{ Non- physical problems }} & \multirow{4}{*}{$\begin{array}{l}\text { No. } \\
30\end{array}$} & \multirow{4}{*}{$\begin{array}{l}\% \text { age } \\
33.34 \%\end{array}$} & \multicolumn{6}{|c|}{ Socio-economic background } \\
\hline & & & & \multicolumn{2}{|c|}{ Low } & \multicolumn{2}{|c|}{ Middle } & \multicolumn{2}{|c|}{ High } \\
\hline & & & & No. & $\%$ age & No. & $\%$ age & No. & $\%$ age \\
\hline $\mathbf{a}$ & Frequent feeling of loneliness & & & 25 & $63.34 \%$ & 5 & $16.67 \%$ & - & - \\
\hline b & Depression & 19 & $21 \%$ & 17 & $88 \%$ & 2 & $12 \%$ & - & - \\
\hline c & Suicidal tendency & 6 & $3 \%$ & 5 & $94.74 \%$ & 1 & $5.27 \%$ & - & - \\
\hline d & Insomnia & 22 & $24.45 \%$ & 19 & $86.37 \%$ & 3 & $13.64 \%$ & - & - \\
\hline e & Fight with friends & 48 & $53.34 \%$ & 41 & $85.42 \%$ & 7 & $14.59 \%$ & - & - \\
\hline \multirow[t]{4}{*}{ f } & Desire for change & & & & & & & - & - \\
\hline & Personality & 33 & $36.67 \%$ & 27 & $81.82 \%$ & 6 & $18.19 \%$ & - & - \\
\hline & Life style & 39 & $43.34 \%$ & 35 & $89.75 \%$ & 4 & $10.26 \%$ & - & - \\
\hline & Face and figure & 5 & $5.56 \%$ & 4 & $80 \%$ & 1 & $20 \%$ & - & - \\
\hline $\mathbf{g}$ & $\begin{array}{l}\text { Absence of knowledge about } \\
\text { menstruation }\end{array}$ & 11 & $12.23 \%$ & 11 & $100 \%$ & - & - & - & - \\
\hline & Change of gender in next life & 28 & $31.12 \%$ & 28 & $100 \%$ & - & - & - & - \\
\hline
\end{tabular}


Non-physical problems: Assessment regarding several non-physical issues was almost similar to the early adolescent group. As presented in Table 4, maximum number of girls 77/90 (85.4\%) had shown a desire for a change in lifestyle and personality. When enquired, many of them 28/90 (31.1\%) subjects spontaneously wished their desire to be a boy instead of a girl. Emotional issues like depression $(21 \%)$, suicidal tendency (3\%) and feeling of loneliness $(33.3 \%)$ were also noted. Insomnia was another such problem seen in $22(24.4 \%)$ elder tribal girls. Moreover it was noted that peer relation was not so good among them as 48/90 girls were noted to pick up fight with friends.

\section{DISCUSSION}

India has the largest adolescent population in the world. About $21 \%$ of Indian population is adolescents. They form a socially important segment of the population. Apart from physical health, a positive social health constitutes holistic health of adolescents. In this research article, we aimed to discuss the magnitude of adolescent physical/non-physical problems along with their social and demographic variables like family, peer relation, personality, culture and other life conditions. This definitely creates awareness amongst them to realize their potential about health and well-being. Moreover it will strengthen tribal health services to meet their need. The study population in the present piece of work was homogenous having similar living condition. 170 adolescent girls were randomly selected from age group 10-19 years, later on divided into one early (10-14 years) and one late (15-19 years) group for the study convenience. In the present study, majority $(81.25 \%$ and $80 \%$ in early and late group respectively) of the girls belong to low economic status. Kuppuswamy's scale was used to determine the socioeconomic status where occupation, literacy rate and family income were used as the indicators. ${ }^{8}$ Socio-demographic data collected during the study showed literacy levels of parents were higher in older adolescent group. According to 1991 census, literacy rate of tribal men is $39.9 \%$ while that of women is $10.2 \%$, which is much lower in comparison to our study. Average literacy rate of Odisha according to 2001 census is $37.3 \%$ and tribal female literacy is $23.3 \%$. So the higher literacy status of subjects in our group might be due to inclusion of more students from advanced tribes like Santhal community, whose ideas and level of education is always greater than that of other tribes. ${ }^{9}$ About the physical problems identified in girls of younger age group (Table 1), majority $62.5 \%$ girls with respiratory problem followed by $22.5 \%$ dental problems, $18.7 \%$ with dental problem and $6.25 \%$ girls with problems associated with menstruation. Where as in older adolescent group, menstruation related problems was the major complaint (Table 2). These above findings justify the study by other authors in this regard. ${ }^{10}$ Table- 3 and Table-4 describe the common adolescent non-physical problems we noted after interviewing both the groups. Depression constituted a major problem with $18 \%$ and $21 \%$ in young and older adolescent girls respectively. Contrary to our findings, another research conducted in New Delhi had shown 57\% of such cases in 15-16 years of age. ${ }^{3}$ According to U.S. Department of Health and Human services (DHHS) 1999 report, Mental Health: A report of the surgeon General, estimates that at least one in five $(20 \%)$ children and adolescent has mental health disorder at some point in their life from childhood to adolescence. $^{11}$ That apart it has been observed that depression is the most common emotional, psychiatric disorder reported in most of the community-based studies. $^{12}$ Moreover in view of the morbidity, it has always been a focus of attention of researchers in India and it has also been observed that it is more common in women than men. In our study, $2 \%$ of young adolescents and $3 \%$ of older adolescents had suicidal tendency, which is lower than general adolescent population (5\%). This definitely needs urgent interventions. ${ }^{13} 43 \%$ of girls in both the age group had shown a poor peer relation with friends as they were found to fight with friends, which reflects a major behavioral disorder in this age group. Almost $50 \%$ of tribal girls in present study $\mathrm{n}$ desired to change the life style and wished to have comfortable life, better education and better social status, which can be compared to the report on status of tribal women by Bhasin et al. ${ }^{14}$ Around $7.5 \%$ of younger adolescent and $5.5 \%$ of older adolescent were concerned about their body image (face and figure). Around $42.5 \%$ of young girls of our study did not have any knowledge about menstruation and $12.2 \%$ of older girls considered it as a disease. Contrary to our findings, several other studies in this regard showed a good awareness level. ${ }^{15,16}$ Observation regarding reproductive knowledge showed that $21.2 \%$ and $32.2 \%$ were ignorant about minimum age of marriage and contraception respectively. About $60 \%$ did not know the right age to become mother, which is a matter of concern. Lots of programmes on awareness and emphasis should be focused on them to guide their overall development. To find out association between the two groups, null hypothesis was assumed. Chi-square test was applied to test significance. Chi-square test with Yates correction came to be 100.07. As the calculated value of Chi-square was greater than the value of Chisquare at $5 \%$ level of significance, it proved that null hypothesis was rejected and it was concluded that there was significant association between the physical problems of young and older adolescent girls. Similarly applying above statistical formula, it was proved that there was a strong association within the sociopsychological problems of adolescent girls of age group 10-14 years and $15-19$ years.

\section{Management}

Having critically analyzed the various psychosocial, emotional and physical problems, following 
recommendations need to be considered to address the current scenario.

1. Awareness/interventional programmes should be undertaken to introduce sex education. This will bridge the knowledge gap in adolescents and will prevent sexual abuse, unsafe sexual practice, which can reduce unwanted pregnancy, sexual transmitted diseases.

2. Life skill education should be part of their curriculum.

3. Various programmes should be adopted to educate adolescents and their parents about nutritional requirement appropriate for their age.

4. Mothers should build confidence in adolescent daughters to get detailed information regarding their health problems. Most of the adolescent's psychosocial disorders remain unidentified because of parent's ignorance and negligence. Parents should be educated and motivated to prevent early marriage, teenage pregnancy.

5. Target population should be redefined to include elders like parents, teachers who will be a part of planning, evaluating and implementing specific programmes for adolescents.

6. Large longitudinal studies are required to pin point specific nature of adolescent problems and the services should be demand driven.

7. Recommendation of adolescent friendly clinics should be there to assure confidentiality and to screen routine adolescent health problems.

\section{CONCLUSION}

Overall on the basis of data available, it was concluded that psychosocial problems and various physical problems were significantly higher in tribal adolescent female population. Lack of knowledge about sexual and reproductive health, were the hot areas of adolescent problems in present study population. Hence there is need for planning of health programmes and establishing adolescent friendly clinics for them. It is also essential to develop specific screening tools for adolescent tribal girls to search for and to eliminate the risk factors as early as possible. Moreover community involvement and awareness should be generated through health education, role-plays to educate parents, as one of the important contributors to this condition could be traced to their poor socioeconomic background with high illiteracy and Santhal tribal character. Focusing these above problems will definitely help the adolescent girls to get a chance to build a safe, happy, healthy life in future.

Funding: No funding sources Conflict of interest: None declared

Ethical approval: The study was approved by the Institutional Ethics Committee

\section{REFERENCES}

1. World health organization. Adolescent friendly health services- an agenda for change. Geneva: World Health Organisation.2002;5.

2. Progress for children: A report card on adolescents. Socio-demographic profile of adolescents. UNICEF. 2012;10.

3. Gupte S. Recent advances in paediatrics (RAP): volume 17. Adolescent. JP Medical Publisher; 2006

4. Census of India. Provisional population totals (Odisha). Paper-1. Series 22. 2001.

5. Twenge GM, Nolen-Hoeksema S. Age, gender, race, economic status and birth cohort differences in children's depression inventory: a meta-analysis. J Abnorm Psychol. 2002;111(4):578-88.

6. Romer D, Stanton BF. Feeling about risk and the epidemic diffusion of adolescent sexual behavior. Prev Sci. 2003;4:39-53.

7. Moffitt TE. Natural histories of delinquency. In H J Kerner and E.Weitekamp, Eds. Cross-national longitudinal research on human development and criminal behaviour. Dordrecht, Kluwer Academic press;1994:3-64.

8. Oberoi SS. Updating income ranges for Kuppuswamy's socio-economic status scale for the year 2014. Indian J Pub Health. 2015;59:156-7

9. Bayer JM. Sociolinguistic perspectives of cultures in transition Indian tribal situation. Language in India. Volume 5. 2005. Available at, www.languageinindia.com/march2005/jennifertribal 1.html. Accessed on 14 March, 2016.

10. Sharma P, Malhotra C, Taneja DK, Saha R. Problems related to menstruation amongst adolescent girls. Indian J Pediatr. 2008;75(2):125-9.

11. Brauner CB, Stephenes CB. Estimating the prevalence of early childhood serious emotional/behavioural disorders: challenges and recommendations. Public Health Rep. 2006;121(3):303-10.

12. Gover S, Dutta A, Avasthi A. An overview of Indian research in depression. India $\mathrm{j}$ psychiatry. 2010;52(7):178-88.

13. Bhave SY. Bhave' text book of adolescent medicine. 1st ed. 2006.

14. Bhasin V. Status of tribal women in India. Stud. Home Comm. Sci. 2007;1(1):1-16.

15. Tarhane S, Kasulkar A. Awareness of adolescent girls regarding menstruation and practices during menstrual cycle. Panacea J Med Sci. 2015;5(1):2932.

16. Nagar S, Aimol KR. Knowledge of adolescent girls regarding menstruation in tribal areas of Meghalaya. Stud Tribes Tribals. 2010;8(1):27-30.

Cite this article as: Das S, Mishra S, Mohanty AK, Sahoo SS. Assessment of adolescent problems in tribal adolescent girls: A cross sectional study. Int $\mathbf{J}$ Community Med Public Health 2016;3:1014-9. 